\title{
DIFERENTES RESPOSTAS DO TECIDO ÓSSEO E ARTICULAR DE RATOS WISTAR, SUBMETIDOS A EXERCÍCIO RESISTIDO, APÓS LESÃO NERVOSA
}

\section{DIFFERENT RESPONSES OF BONE AND ARTICULAR TISSUE OF WISTAR RATS, SUBMITTED TO EXERCISE RESISTED, AFTER NERVOUS INJURY}

\author{
Vinícius Baretta' ${ }^{1}$ Daniele Pelissari' ${ }^{1}$ Assis Roberto Escher ${ }^{2}$, Rose Meire Costa Brancalhão ${ }^{3}$, Lucinéia de \\ Fátima Chasko Ribeiro ${ }^{4}$, Gladson Ricardo Flor Bertolini ${ }^{5}$
}

\footnotetext{
Autor para correspondência: Gladson Ricardo Flor Bertolini - gladsonricardo@gmail.com 'Acadêmico (a) do curso de Fisioterapia da Universidade Estadual do Oeste do Paraná (Unioeste), Cascavel, Paraná, Brasil.

${ }^{2}$ Técnico do laboratório de Estudo das Lesões e Recursos Fisioterapêuticos da Universidade Estadual do Oeste do Paraná (Unioeste), Cascavel, Paraná, Brasil.

${ }^{3}$ Bióloga. Pós-doutora em Biologia Celular. Professora da Universidade Estadual do Oeste do Paraná (Unioeste), Cascavel, Paraná, Brasil. ${ }^{4}$ Bióloga. Doutora em Ciências Biológicas. Professora da Universidade Estadual do Oeste do Paraná (Unioeste), Cascavel, Paraná, Brasil. ${ }^{5}$ Fisioterapeuta. Doutor em Ciências da Saúde Aplicadas ao Aparelho Locomotor. Professor da Universidade Estadual do Oeste do Paraná (Unioeste), Cascavel, Paraná, Brasil.
}

RESUMO | Objetivo: analisar o efeito do exercício resistido de subida em escadas nos tecidos ósseo e articular, após lesão compressiva do nervo isquiático de ratos Wistar. Material e Métodos: 32 ratos foram divididos aleatoriamente em 4 grupos, com 8 animais em cada, G1 (controle), G2 (exercício), G3 (lesão) e G4 (lesão e exercício). Após a lesão nervosa G2 e G4 foram submetidos ao exercício resistido de subida em escada, durante 5 dias na semana, com intervalo de 2 dias, por 21 dias. Os animais foram eutanasiados e as articulações do joelho e tíbias do membro pélvico lesionado foram coletadas, e seguiram o processamento padrão para análises em microscopia de luz. Resultados: $O$ tecido ósseo apresentou alterações significativas, em relação a análise morfométrica da área do canal medular e contagem e osteócitos, porém, não foi observada diferença significativa em relação a análise da espessura do osso cortical. Na cartilagem articular do joelho foram observadas discretas alterações morfológicas entre os grupos, como a presença de clones celulares no grupo G3 e remodelagem no grupo G4. Conclusão: a lesão do nervo isquiático em ratos Wistar trouxe efeitos deletérios ao tecido ósseo e articular. Também foi observado que o exercício físico resistido em subida de escada não trouxe alterações ao tecido ósseo dos animais, porém, foi eficaz ao retorno às características normais da cartilagem articular lesionada, e demonstrou aumento da evidencia da tidemark, em animais não lesionados.

\begin{abstract}
Objective: To analyze the effect of resistance exercise climb stairs in bone tissue and articular after compression injury of the sciatic nerve of Wistar rats. Methods: 32 rats were randomly divided into 4 groups with 8 animals in each, G1 (control), G2 (exercise), G3 (injury) and G4 (injury and exercise). After nerve injury $G 2$ and $G 4$ were submitted to resistance exercise climb stairs, for 5 days a week, with two days interval for 21 days. After the experiment, the animals were euthanized and the knee and tibia of the injured hindlimb were collected, and followed the standard processing for analysis by light microscopy. Results: The bone tissue change significantly in relation to morphometric analysis of the area of the spinal canal and counting and osteocytes, however, was not observed significant difference in the analysis of the thickness of the cortical bone. A joint tissue were observed discrete morphological changes between the groups. Conclusion: The sciatic nerve injury in rats brought deleterious effects on bone tissue and articular. It was also observed that resistance exercise in stair climbing brought no changes to bone tissue of animals, however, it was effective to return to the normal characteristics of the injured joint, and showed increased evidence of tidemark in uninjured animals.
\end{abstract}

Keywords: exercise resisted; injury nervosa peripheral; bone tissue; articular tissue.

Palavras-chave: exercício resistido; lesão nervosa periférica; tecido ósseo; tecido articular. 


\section{INTRODUÇÃO}

Diferentemente do sistema nervoso central, o SNP não possui uma proteção óssea, como o crânio e a coluna vertebral, o que o deixa mais vulnerável ao surgimento de injúrias. Essas lesões podem surgir de diferentes formas, como: esmagamento, estiramento, compressão, avulsão e secção total ou parcial no nervo', que são importantes causas de incapacitação física e perda total ou parcial de atividades produtivas, tendo como consequência a diminuição da qualidade de vida ${ }^{2}$. Dentre as lesões de nervo periférico, a do nervo isquiático corresponde a $4^{a}$ maior incidência $(10,7 \%)^{3}$, acarretando dor ao longo do trajeto inervado. Esta condição denominada ciatalgia ou lombociatalgia, se caracteriza por distúrbios sensoriais e fraqueza dos músculos do membro inferior inervado por ele ${ }^{4}$.

Uma das consequências da lesão pode ser a descarga desigual de peso durante a marcha, desencadeada pelos processos de dor, parestesia e paresia. Sabe-se que a carga mecânica influencia no desenvolvimento e manutenção de tecidos articulares, incluindo a cartilagem ${ }^{5}$. A carga mecânica também é um importante estímulo para o remodelamento ósseo, induzindo a uma melhor fixação de cálciő.

Medidas terapêuticas visam reduzir os prejuízos causados pela inervação deficiente, bem como os déficits ocasionados por este quadro. Dentre os recursos fisioterapêuticos destacam-se os exercícios físicos resistidos, que atuam na manutenção da força e ganho de massa muscular, sendo que estes efeitos podem ser observados tanto em humanos quanto em modelos animais ${ }^{7}$. Também, a atividade física pode causar alterações no metabolismo do tecido ósseo, por descarga mecânica e fatores hormonais, aumentando a massa óssea ${ }^{8}$.

Uma forma de exercício físico resistido é o de subida em escada, citado na literatura com várias finalidades como, por exemplo, a indução da hipertrofia muscular ${ }^{7}$, regeneração axonal ${ }^{9}$, reversão dos efeitos deletérios da ovariectomia sobre o tecido ósseo ${ }^{10}$; porém, pouco se sabe sobre a contribuição deste protocolo em lesões de SNP.

Há também carência na literatura de trabalhos relatando a associação entre protocolos de exercício resistido, o desuso do membro lesionado e os tecidos articular e ósseo. Desta forma, o objetivo do presente estudo foi analisar o efeito do exercício de subida em escada sobre a morfologia da articulação do joelho e histomorfometria do tecido ósseo da tíbia, após lesão compressiva do nervo isquiático de ratos Wistar.

\section{MATERIAIS E MÉTODOS}

Ratos machos da linhagem Wistar, com idade de 10 semanas, obtidos no Biotério da Universidade Estadual do Oeste do Paraná (Unioeste), foram mantidos em gaiolas plásticas de polipropileno, com acesso a água e ração à vontade, temperatura ambiente $25^{\circ} \mathrm{C}$, fotoperíodo claro/escuro de 12 horas, e agrupados em 3 animais por caixa. O estudo conduziu-se segundo as Normas Internacionais de Ética na Experimentação Animal, sendo aprovado pelo Comitê de Ética em Uso Animal da Unioeste.

Os animais foram divididos aleatoriamente em 4 grupos experimentais, com 8 ratos em cada grupo:

- G1: controle

- G2: exercício resistido em escada.

- G3: compressão do nervo isquiático.

- G4: compressão do nervo isquiático e exercício de subida em escada.

\section{Protocolo de Lesão}

Para o modelo experimental da axonotmese do nervo isquiático, os animais de G3 e G4 foram pesados e anestesiados, previamente ao procedimento cirúrgico, com injeção intraperitoneal de cloridrato de quetamina $(80 \mathrm{mg} / \mathrm{Kg})$ e xilazina $(12 \mathrm{mg} / \mathrm{Kg})$. Após verificação do estado de consciência do animal (observado pela ausência de resposta motora ao pinçamento da cauda e pregas interdigitais), este foi posicionado em decúbito ventral, mantendo-se os membros escapulares e pélvicos em abdução. Realizou-se a tricotomia em terço médio da coxa posterior direita e assepsia do local com uso de polivinilpirrolidona-iodo.

Em seguida, realizou-se uma incisão, paralela às 
fibras do músculo bíceps femoral, expondo o nervo isquiático e subsequente compressão do mesmo, com uso de pinça hemostática, por um período de 30 segundos. A pressão gerada foi padronizada pelo fechamento da mesma no $2^{\circ}$ dente da cremalheira. Após o pinçamento realizou-se uma marcação no local da lesão, por sutura epineural, utilizando fio de nylon 10.0. Todas as lesões foram realizadas pelo mesmo avaliador, a fim de se evitar variações no procedimento. Por fim, foi feita a sutura com pontos simples, utilizando fio de nylon monofilamento por planos, aplicado iodo sobre a incisão e então, os animais foram alojados nas mesmas condições précirúrgicas.

\section{Protocolo de Exercício}

protocolo de exercício resistido foi adaptado de Hornberger e Farrar ${ }^{7}$. Para sua realização utilizouse uma escada vertical, feita de madeira com 67 degraus de ferro, com espaçamento de $1 \mathrm{~cm}$ entre cada degrau, altura de $118 \mathrm{~cm}$, largura $20,5 \mathrm{~cm}$ e inclinação de aproximadamente $60^{\circ}$. Na parte superior da escada foi utilizada uma gaiola, com uma altura de $18,5 \mathrm{~cm}$ e $15 \mathrm{~cm}$ de largura, que serviu como abrigo durante o período de descanso entre as séries.

Antes da cirurgia de compressão do nervo isquiático, os animais do $G 2$ e $G 4$ foram submetidos a um protocolo de familiarização com a escada vertical. O protocolo consistiv em três ensaios por dia durante duas semanas de treinamento, com intervalo de 2 dias, e nenhum tipo de estímulo doloroso foi utilizado. A partir da segunda semana, os animais começaram a treinar utilizando um aparato de carga de $100 \mathrm{~g}$, preso na porção proximal da cauda.

Após a cirurgia, os animais de G2 e G4 foram submetidos ao exercício resistido durante cinco dias por semana com intervalo de dois dias, durante três semanas. Este tratamento iniciou a partir do $3^{\circ}$ dia após o procedimento cirúrgico ( $\left.3^{\circ} \mathrm{PO}\right)$. $O$ exercício consistiu em duas séries de 10 subidas consecutivas na escada, com um intervalo de 60 segundos após cada sessão para descanso.

\section{Análise histológica}

Após o período de tratamento de cada grupo, os animais foram pesados, anestesiados e decapitados em guilhotina. $O$ membro pélvico direito foi dissecado e as articulações do joelho e tíbias coletadas, fixadas em Metacarn durante 24 horas, e em seguida lavadas em água destilada. Para descalcificação do tecido, utilizou-se o ácido tricloroacético (TCA) a 5\%, por 10 dias. As amostras passaram pela desidratação por 1 hora nos álcoois $70 \%, 80 \%$ e $90 \%, 95 \%$ overnight, e para o álcool $100 \%$ por 4 banhos de 1 hora cada.

Em seguida, o material foi diafanizado, impregnado e incluído em parafina, os blocos cortados, com 7 $\mu \mathrm{m}$ de espessura em micrótomo Olympus CUT 4055, e as lâminas coradas em hematoxilina e eosina para serem analisadas e fotomicrografadas em microscópio de luz (Olympus ${ }^{\circledR}$ ).

As imagens do tecido articular foram capturadas e analisadas quanto a sua morfologia, no caso do tecido ósseo da tíbia, foram realizadas análises morfométricas da espessura do osso cortical, área do canal medular e número de osteócitos, com auxílio do Programa Image Pro Plus 6.0 (USA).

\section{Análise estatística}

Os dados numéricos foram analisados quanto à sua normalidade por meio do teste de Shapiro-Wilk, posteriormente foi realizado ANOVA unidirecional, com pós-teste de Tukey, em todos os casos o nível de significância aceito foi $5 \%$.

\section{RESULTADOS E DISCUSSÃO}

A análise dos dados mostra que em relação à área do canal medular, houve diferença significativa entre os grupos lesão (G3) e lesão + exercício (G4) com relação ao grupo controle $(G 1)$ e se repetiu com relação ao grupo exercício (G2) (tabela 1). 
Tabela 1. Apresentação dos resultados em média e desvio-padrão, para as variáveis morfométricas do tecido ósseo (área do canal medular, contagem de osteócitos e espessura do osso cortical), para os diferentes grupos. Nas comparações letras iguais demonstram semelhança estatística.

\begin{tabular}{lcccc}
\hline & G1 & G2 & G3 & G4 \\
\hline $\begin{array}{l}\text { Área do } \\
\begin{array}{l}\text { Canal } \\
\text { Medular } \\
\left(\mu \mathrm{m}^{2}\right)\end{array}\end{array}$ & $\begin{array}{l}38091.8 \pm 969.6 \\
\text { Número de }\end{array}$ & $878082.2 \pm 976.9$ & $31219.1 \pm 1103.7$ & $32410.8 \pm 1415.1$ \\
osteócitos & & $\mathrm{a}$ & $\mathrm{b}$ & $\mathrm{b}$ \\
$\begin{array}{l}\text { Espessura do } \\
\text { osso cortical }\end{array}$ & $162.8 \pm 4.6 \mathrm{a}$ & $162.6 \pm 15.4 \mathrm{a}$ & $156.9 \pm 3.4 \mathrm{a}$ & $173.4 \pm 11.4 \mathrm{a}$ \\
$(\mu \mathrm{m})$ & & $903.0 \pm 15.1 \mathrm{a}$ & $852.8 \pm 33.0 \mathrm{~b}$ & $832.6 \pm 28.3 \mathrm{~b}$ \\
\hline
\end{tabular}

Em relação ao número de osteócitos, houve diferença significativa entre o grupo G2 com G3 e G4 (tabela 1). Não foi observada diferença significativa em relação à análise da espessura do osso cortical (tabela 1).

O presente estudo buscou analisar a ação do exercício resistido de subida em escada na histomorfometria do tecido ósseo após lesão compressiva do nervo isquiático de ratos Wistar. Foi observado que os animais submetidos à lesão obtiveram menores valores de área do canal medular e número de osteócitos, porém não houve alterações em relação à espessura do osso cortical entre os grupos (tabela 1).

Os achados sugerem que a lesão do nervo periférico trouxe efeitos deletérios ao tecido ósseo dos animais, o que pode ser explicado pela imobilidade e descarga desigual de peso entre os membros decorrente da lesão nervosa, que reduzem o estímulo necessário pelo crescimento e remodelamento ósseo ${ }^{11}$. Em outro estudo que visava verificar alterações histológicas do tecido ósseo periarticular e cartilaginoso de ratos Wistar decorrentes da imobilização, foi encontrada diminuição do número de osteócitos do membro imobilizado em comparação ao contralateral ${ }^{12}$, corroborando com o encontrado no presente estudo. Ocarino e Serakides ${ }^{8}$ apontaram que a atividade física pode causar alterações no metabolismo do tecido ósseo por descarga mecânica e fatores hormonais aumentando a massa óssea. $E$, segundo Tagliaferri et al. ${ }^{13}$ há uma importante conexão entre os tecidos musculares e ósseo, sendo que diversos fatores produzidos pelo primeiro influem na qualidade óssea. Porém, mesmo que indiretamente, no presente estudo não foram encontrados indícios de aumento da massa óssea.

Em relação ao tecido articular, $G 1$ demonstrou morfologia característica da articulação do joelho, apresentando superfície articular com condrócitos dispostos nas quatro camadas, sem alterações no osso subcondral. A zona profunda com os condrócitos organizados em lacunas, separada da zona calcificada, por uma linha, a tidemark (figura 1A). No grupo que somente realizou o exercício de subida em escada (G2), verificou-se morfologia característica desta articulação, com aspecto do grupo controle, porém, com uma tidemark mais evidente (figura 1B), podendo ser um indicativo de efeito positivo do exercício sobre a articulação ${ }^{14}$. Em G3, notou-se a presença de mais grupos isógenos (clones celulares) (figura 1C), apontando um efeito deletério da lesão nervosa. 

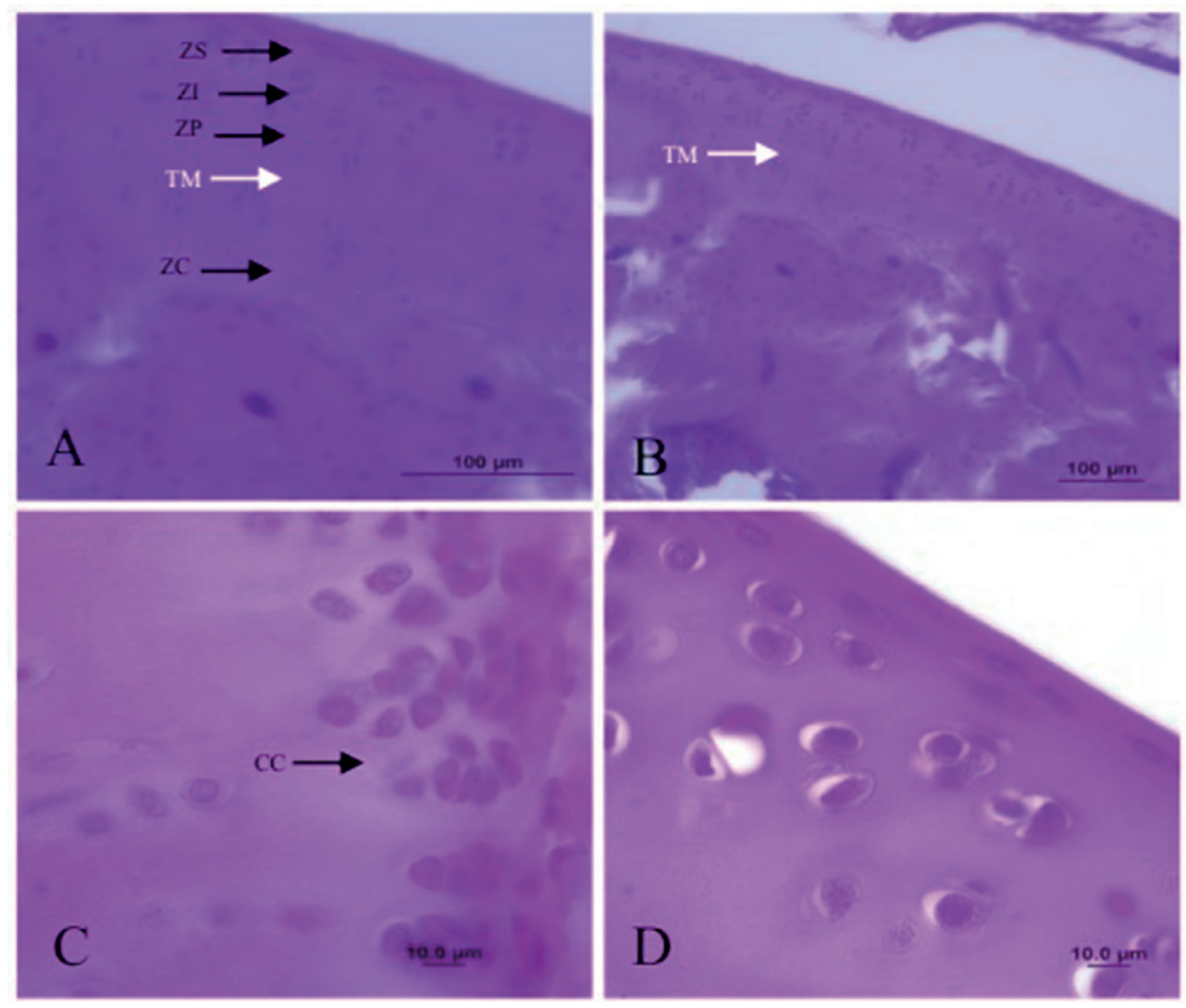

Figura 1: Fotomicrografias da cartilagem articular da articulação do joelho de ratos Wistar, corte sagital, coloração HE. Em A G1 (grupo controle), mostrando as zonas da cartilagem articular: superficial (ZS), intermédia (ZI), profunda (ZP), tidemark (TM) e zona calcificada (ZC). Em B G2 (grupo exercício resistido), observa-se a tidemark mais evidente (TM). Em C G3 (grupo lesão nervosa), aumento de grupos isógenos (clones celulares) (CC). Em D G4 (grupo lesão nervosa e exercício), apresentando organização normal da cartilagem articular.

Segundo Cavalcante et al. ${ }^{15}$, uma vez que as lesões nervosas interrompem a comunicação neuromuscular, causam a atrofia dos músculos efetores, levando ao comprometimento da biomecânica da articulação e consequentemente a redução da amplitude de movimento e diminuição da descarga de peso no membro afetado, o que leva a modificações nas estruturas da articulação, em razão da influência que a transferência de carga desempenha na homeostase dos tecidos articulares ${ }^{5}$.

No entanto, as alterações morfológicas na articulação do joelho, apresar de estarem presentes, foram pouco evidentes após lesão do nervo isquiático, o que se justifica devido ao fato de que esta articulação e o músculo, responsável pelo mecanismo de extensão do joelho, serem inervadas principalmente pelo nervo femoral ${ }^{16}$.

No G4 foi observado uma reorganização dos grupos isógenos da cartilagem articular e as características morfológicas se apresentaram semelhantes ao do grupo controle, demonstrando que o exercício físico resistido foi efetivo na sua remodelação (figura 1D). Vale salientar que o exercício físico intenso é utilizado como modelo para produção de osteoartrose ${ }^{17}$, denotando a importância que o exercício seja dosado adequadamente, como em estudo anterior apontando para efeitos benéficos sobre a cartilagem do exercício de subida em escada para ratas submetidas à ooforectomia e imobilização de membros pélvicos ${ }^{18}$.

Morimoto et al. ${ }^{19}$ colocam que o exercício físico promove redução da dor e recuperação funcional da articulação após lesão nervosa, bem como diminui a limitação articular. Jang e Lee ${ }^{20}$ verificaram que o exercício em esteira, após lesão nervosa isquiática, melhora a biomecânica das articulações do tornozelo, joelho e quadril durante a marcha. Assim, pode-se constatar que o exercício produz efeitos analgésicos e atua na regeneração funcional do nervo periférico ${ }^{21}$, restaurando a função motora - que restabelece a marca e com isso restaura os parâmetros necessários para a manutenção morfológicos dos tecidos articulares. Contudo, 
Oliveira et al. ${ }^{22}$ utilizando de 30 minutos diários de natação livre e/ou eletroestimulação neuromuscular, durante 22 dias, após axonotmese em nervos isquiáticos de ratos Wistar, não observaram influências positivas nos aspectos histomorfométricos e funcionais, com relação ao reparo nervos; quando as técnicas foram utilizadas isoladamente, e quando associadas houve atraso na recuperação funcional. Resultados semelhantes foram observados em outros estudos, como o de Sobral et al..$^{23}$ que, em semelhante modelo de lesão nervosa, avaliaram o efeito de dois protocolos de exercício em esteira elétrica, iniciando precoce ou tardiamente, e não observaram efeitos significativos na avaliação funcional e morfométrica. Takeda et al. ${ }^{24}$ utilizando um ambiente enriquecido, com escada, rodas para exercício, rampas e mudanças de locais de alimentos, favorecendo assim a prática de exercícios por ratos com lesão nervosa, também não visualizaram efeitos sobre o reparo nervoso.

Com relação ao protocolo de exercício resistido de subida em escada, a padronização de 21 dias de duração do tratamento, baseou-se em Gorio et al. ${ }^{25}$, que ao estudar em ratos o processo de reinervação do músculo extensor longo dos dedos, após lesão por esmagamento do nervo isquiático, notaram ausência de axônios no músculo quando analisado em 10 dias após axonotmese. Com 15 dias, $25 \%$ das fibras foram reinervadas e entre 21 e 25 dias, a maioria das fibras musculares apresentavam reinervação. Com 26 dias era evidente a eliminação sináptica e, por volta de 90 dias as junções neuromusculares já estavam recuperadas. Portanto, o período de 21 dias é considerado suficiente para demonstrar a influência do exercício resistido de subida em escada sobre a regeneração nervosa e recuperação funcional a partir de análise dos tecidos ósseo e articular.

\section{CONCLUSÃO}

A partir dos resultados pode-se concluir que a lesão do nervo isquiático em ratos Wistar trouxe efeitos deletérios ao tecido ósseo da tíbia. Também foi observado que o exercício físico resistido em subida de escada nos parâmetros utilizados, não alterou os aspectos morfométricos do tecido ósseo dos animais. Em relação ao tecido articular, pode-se concluir que a lesão compressiva do nervo isquiático, desencadeou discretas modificações na cartilagem articular com a presença de clones celulares do joelho de ratos Wistar. Também pode-se notar que a aplicação do protocolo de exercício de subida em escada, aumentou a evidencia da tidemark, e em animais lesionados, foi eficaz no retorno das características normais da cartilagem articular.

\section{AGRADECIMENTOS}

Ao Conselho Nacional de Desenvolvimento Científico e Tecnológico (CNPq) e à Fundação Araucária, pela concessão de bolsas de Iniciação Científica.

\section{CONTRIBUIÇÕES DOS AUTORES}

Baretta $\vee$ e Pelissari D participaram da concepção do projeto, coleta e análise de dados, e redação do artigo; Escher AR participou da coleta e análise de dados, e revisão crítica do artigo; Brancalhão RMC, Ribeiro LFC e Bertolini GRF participaram da concepção do projeto, da análise de dados, e da revisão crítica do artigo.

\section{CONFLITO DE INTERESSES}

Nenhum conflito financeiro, legal ou político envolvendo terceiros (governo, empresas e fundações privadas, etc.) foi declarado para nenhum aspecto do trabalho submetido (incluindo mas não limitandose a subvenções e financiamentos, conselho consultivo, desenho de estudo, preparação de manuscrito, análise estatística, etc).

\section{REFERÊNCIAS}

1. Udina E, Cobianchi S, Allodi I, Navarro X. Effects of activity-dependent strategies on regeneration and plasticity after peripheral nerve injuries. Ann Anat. 2011 ; 193(4):34753. doi: 10.1016/i.aanat.2011.02.012

2. Sebben AD, Cocolichio F, Schmitt APV, Curra MD, da Silva PV, Tres GL et al. Efeito de fatores neurotróficos sobre o reparo de nervo periférico. Sci Med (Porto Alegre). $2011 ; 21(2): 81-9$

3. Daneyemez M, Solmaz I, Izci Y. Prognostic factors for the surgical management of peripheral nerve lesions. Tohoku J Exp Med. 2005;205(3):269-75

4. Dosani A, Giannoudis PV, Waseem M, Hinsche A, Smith RM. Unusual presentation of sciatica in a 14-year-old girl. Injury. 2004;35(10):1071-2. doi: 10.1016/S0020- 
1383(03)00104-9

5. Vanwanseele B, Lucchinetti E, Stüssi E. The effects of immobilization on the characteristics of articular cartilage: current concepts and future directions. Osteoarthr Cartil. 2002 May; 10(5):408-19. doi: 10.1053/joca.2002.0529

6. Esteves ACF, Bizarria FS, Coutinho MPG, Barreto TKDP, Brasileiro-Santos MS, de Moraes SRA. A natação minimiza o retardo no crescimento somático e ósseo de ratos? Rev Bras Med do Esporte. 2010;16(5):368-72. doi: 10.1590/S151786922010000500010

7. Hornberger T, Farrar R. Physiological hypertrophy of the FHL muscle following 8 weeks of progressive resistance exercise in the rat. Can J Appl Physiol. 2004 Feb;29(1):1631

8. Ocarino NDM, Serakides RR. Efeito da atividade física no osso normal e na prevenção e tratamento da osteoporose. Rev Bras Med do Esporte. 2006;1 2(3):164-8. doi: 10.1590/ S1517-86922006000300011

9. Ilha J, Araujo RT, Malysz T, Hermel EES, Rigon P, Xavier LL et al. Endurance and resistance exercise training programs elicit specific effects on sciatic nerve regeneration after experimental traumatic lesion in rats. Neurorehabil Neural Repair. 2008;22(4):355-66. doi: $10.1177 / 1545968307313502$

10. Shiguemoto GE, Prestes J, Leite RD, Pereira GB, Pontes CLS, D'Ávila FV et al. Effects of resistance training on matrix metalloproteinase- 2 activity and biomechanical and physical properties of bone in ovariectomized and intact rats. Scand J Med Sci Sport. 2012;22(5):607-17. doi: $10.1111 /$ j.16000838.2010.01284.x

11. Kujawa M, Baran W, Jankowska-Steifer E. Quantitative ultrastructural changes in satellite cells of rats immobilized after soleus muscle denervation. Exp Mol Pathol. 2005;78(1):78-85. doi: 10.1016/i.yexmp.2004.08.007

\section{Portinho D, Boin VG, Bertolini GRF. Effects of} immobilization and remobilization on bone tissue and cartilage in Wistar rats | Efeitos sobre o tecido ósseo e cartilagem articular provocados pela imobilização e remobilização em ratos Wistar. Rev Bras Med do Esporte. 2008;1 4(5):408-1 1. doi: 10.1590/S151786922008000500001

13. Tagliaferri C, Wittrant Y, Davicco M-J, Walrand S, Coxam V. Muscle and bone, two interconnected tissues. Ageing Res Rev. 2015;21:55-70. doi: 10.1016/i.arr.2015.03.002

14. Broom ND, Poole CA. A functional-morphological study of the tidemark region of articular cartilage maintained in a non-viable physiological condition. J Anat. 1982;135(1):6582

15. Cavalcante VEV, Silva LGM, Montenegro EJN, Filho NTP. Efeito da eletroestimulação no músculo desnervado de animais: revisão sistemática. Fisioter Mov. 2012;25(3):669-
16. Moore KL, Dalley II AF, Agur AMR. Anatomia orientada para a clínica. 7. ed. Rio de Janeiro: Koogan; 2014. P. 1307

17. Liu S-S, Zhou P, Zhang Y. Abnormal expression of key genes and proteins in the canonical $W n t / \beta$-catenin pathway of articular cartilage in a rat model of exercise-induced osteoarthritis. Mol Med Rep. 2016;13(3):1999-2006. doi: $10.3892 / \mathrm{mmr} .2016 .4798$

18. Simas JMM, Kunz RI, Brancalhão RMC, Ribeiro LFC, Bertolini GRF. Efeitos do exercício físico sobre a cartilagem de ratas ooforectomizadas submetidas à imobilização. Einstein. 2015;13(4):574-9. doi: 10.1590/S1679$45082015 \mathrm{AO} 3418$

19. Morimoto A, Winaga $H$, Sakurai $H$, Ohmichi $M$, Yoshimoto $\mathrm{T}$, Ohmichi $\mathrm{Y}$ et al. Treadmill running and static stretching improve long-lasting hyperalgesia, joint limitation, and muscle atrophy induced by cast immobilization in rats. Neurosci Lett. 2013;534:295-300. doi: 10.1016/i.neulet.2012.11.009

20. Jang S-H, Lee J-H. Effects of physical exercise on the functional recovery of rat hindlimbs with impairments of the sciatic nerve as assessed by $2 \mathrm{D}$ video analysis. J Phys Ther Sci. $2015 ; 27(3): 935-8$. doi: 10.1589 /ipts.27.935

21. Lee YS, Bae SH, Hwang JA, Kim KY. The effects of kinesio taping on architecture, strength and pain of muscles in delayed onset muscle soreness of biceps brachii. J Phys Ther Sci. $2015 ; 27(2): 457-9$. doi: 10.1589/ipts.27.457

22. Oliveira LS, Sobral LL, Takeda SYM, Betini J, Guirro RRJ, Somazz MC et al. Estimulación eléctrica y natación en la fase aguda de la axonotmesis: influencia sobre la regeneración nerviosa y la recuperación funcional. Rev Neurol. 2008;47(1):11-5

23. Sobral LL, Oliveira LS, Takeda SYM, Somazz MC, Montebelo MIL, Teodori RM. Exercício imediato versus tardio na regeneração do nervo isquiático de ratos após axoniotmese: análise histomorfométrica e funcional axonotmesis : histomorphometric and functional analysis. Rev Bras Fisioter. 2008; 12 (4):31 1-6. doi: 10.1590/S141335552008000400010

24. Takeda SYM, Oliveira LS De, Sobral LL, Somazz MC, Montebelo MIL, Teodori RM. Regeneración nerviosa periférica en ratones expuestos a un ambiente enriquecido. Rev Neurol. 2008;47(4):185-90

25. Gorio A, Carmignoto G, Finesso M, Polato P, Nunzi MG. Muscle reinnervation - II. Sprouting, synapse formation and repression. Neuroscience. 1983;8(3):403-16 